\title{
EL «ORIENTALISMO GRECO-BIZANTINO» \\ EN LA ESPAÑA DE FINALES DEL SIGLO XIX: ANTONIO DE ZAYAS BEAUMONT
}

\author{
CARLOS MARTÍNEZ CARRASCO \\ UNIVERSIDAD DE GRANADA. España
}

\begin{abstract}
Resumen: La llegada del diplomático español Antonio de Zayas se produjo en un año clave para el Imperio otomano. En dos obras cuyo hilo conductor fue su experiencia en la Sublime Puerta, dejó constancia de las condiciones de vida de los griegos, transmitiendo una visión particular del pasado bizantino. Estas características llevan a plantear la existencia de un «orientalismo grecobizantino» que se desarrolla en paralelo al orientalismo clásico.
\end{abstract}

Palabras clave: Antonio de Zayas. Turquía. Grecia. Bizancio. Relaciones Iglesia ortodoxaIglesia católica. Orientalismo.

\section{“GRECO-BYZANTINE ORIENTALISM"IN LATE 19TH CENTURY SPAIN: ANTONIO DE ZAYAS BEAUMONT.}

\begin{abstract}
The arrival of the Spanish diplomat Antonio de Zayas came at a key year for the Ottoman Empire. He wrote two works about his experience in the «Sublime Porte», in which he reflected the living conditions of the Greek population and his particular view of the Byzantine past. These characteristics lead me to suggest the existence of a «Greek-Byzantine Orientalism», which runs parallel with the Classical Orientalism.
\end{abstract}

Key words: Antonio de Zayas. Turkey. Greece. Byzantium. Relations between Orthodox and Catholic Churches. Orientalism.

Recibido: 25.01.2016 - Aceptado: 4.04.2016

\section{Correspondencia: Carlos Martínez Carrasco.}

Email: cmtnez@ugr.es

Licenciado en Historia. Máster en Historia y Culturas Semíticas.

Becario FPU. Profesor de Historia medieval en la UGR e investigador del C.E.B.N.Ch.

Universidad de Granada. Centro de Estudios Bizantinos, Neogriegos y Chipriotas.

Telf.: 637934798.

Dirección: Gran Vía n 9, $2^{\circ}$ A, 18001 Granada (España). 


\section{A ntonio de Zayas Beaumont, duque de Amalfi (1871-1942) \\ sirvió en la embajada española de Estambul como Secretario \\ 1 de Tercera Clase, tomando posesión del puesto en el mes de} febrero de 1897, que abandonó tras un año y medio ${ }^{1}$. De su estancia en la capital turca surgirán dos libros de muy distinto género: Joyeles bizantinos (1902)2, una colección de más de un centenar de poemas en los que plasma escenas y escenarios de la antigua Constantinopla; y A orillas del Bósforo (1912) ${ }^{3}$, en el que el diplomático español dejó, en prosa, un vívido relato de su estancia, describiendo la vida cotidiana en Estambul, las minorías que en ella vivían, junto a otras consideraciones de tipo político, religioso e histórico.

La lectura que se propone en este estudio está alejada del mero análisis filológico que, por otro lado, ya se ha abordado. Tampoco se buscará redundar sobre los motivos del orientalismo occidental centrado en trazar la imagen que de los musulmanes y algunas de sus instituciones, como el harén, daba De Zayas. Se tratará de exponer la idea que este autor transmite en ambos libros citados acerca de Bizancio y lo bizantino, así como de la situación en la que vivían los griegos y cómo fueron percibidos por este diplomático.

Los temas elegidos para el presente estudio los brinda el propio A. de Zayas. En la carta-prólogo con la que abre Joyeles... reconoce que al poco de tomar posesión de su cargo, estalló la guerra entre Grecia y Turquía ${ }^{4}$, la conocida como Guerra de Treinta Días (abril-mayo, 1897)5. Asimismo, en el prólogo de A orillas... pone como telón de fondo la cuestión armenia, el problema cretense y la guerra greco-turca, «la actual conflagración en la Península Ilírica» ${ }^{6}$.

Aunque no se trate de un estudio literario, conviene partir del contexto cultural en el que Antonio de Zayas escribió sus obras.

1 Sobre este y otros datos biográficos, véase: Correa Ramón, A. (2005), «Introducción» en De Zayas, A., Obra poética, edición de Amelina Correa Ramón, Sevilla: Fundación José Manuel Lara, pp. 11-99, espec. 19-20; Correa Ramón, A. (2005), «La experiencia del Oriente Bizantino. Vida y literatura del poeta Antonio de Zayas de Beaumont», El viajero histórico 23, Granada: El Legado Andalusí, p. 4; Primo Cano, C. (2010), «Calas en torno a la visión orientalista de Antonio de Zayas», Dicenda. Cuadernos de Filología Hispánica 28, pp. 153-184, espec. 155; Nebot Nebot, J. V. (2013-2014), Antonio de Zayas. Poética y poesías parnasianas (1892-1902), tesis doctoral presentada en la Universitat Jaume I de Castellón, p. 33.

2 De Zayas, A. (1902), Joyeles bizantinos, Madrid: Imprenta de A. Marzo.

3 De Zayas, A. (1912), A orillas del Bósforo, Madrid: Imprenta de Juan Pueyo.

4 De Zayas, A., Joyeles, p. 5.

5 Sobre esta guerra, véase: AA.VV. (1999), A History of the Hellenic Army (1821-1997), Atenas: Army History Directorate, pp. 68-74.

De Zayas, A., A orillas, p. 9. 
A finales de siglo, una de las principales corrientes literarias en Europa fue el parnasianismo, en la que se puede inscribir por sus temas y forma métrica, los Joyeles bizantinos. Surgió como una reacción frente a las formas del romanticismo tardío, caracterizado por mantener cualquier sentimentalismo al margen del poema, dotándolo de una frialdad impersonal. Hay un cierto rigor formal, empleándose formas métricas y estrofas clásicas, en temas exóticos o grecolatinos, de los que el orientalismo es una variante más. Una vuelta de tuerca de este parnasianismo fue el decadentismo finisecular ${ }^{7}$, con ciertos aires aristocráticos, que sobrevuela las páginas de las dos obras que nos ocupan. $\mathrm{Y}$ aunque se busquen los puntos diferenciadores con respecto a la imagen tradicional del orientalismo, en lo que se puede llamar el «orientalismo grecobizantino», subyace un sustrato común al resto de los pueblos orientales. De Zayas, igual que el resto de los escritores contemporáneos, busca presentar al otro, al oriental de manera completamente distinta a la sociedad occidental burguesa, resaltando las diferencias con respecto a los valores y al pasado de la Europa occidental ${ }^{8}$, a pesar de que se compartiera una misma religión, si bien con importantes matices.

Las primeras impresiones recogidas por el diplomático recién llegado a Estambul están marcadas por la turba que lo recibió en la estación de Sirkedji, la suciedad de las calles y las casas viejas ${ }^{9}$. Un subdesarrollo acentuado por el puente de madera que unía Pera -donde se instalará junto con el resto de la legación española en el Hotel Pera Palace- con Estambul, poco acorde con el progreso experimentado por el resto de las naciones «civilizadas», todo marcado por la venalidad y el nepotismo del gobierno otomano ${ }^{10}$. Y en medio de este cuadro tremendista del estado en el que se hallaba la otrora brillante capital de Bizancio, resalta De Zayas a los perros. Estos animales eran, según el poeta y diplomático, los verdaderos encargados de la limpieza en la ciudad, ya que encontraban alimento en los montones de basura que se repartían a lo largo y ancho de Estambul. Unos perros que hicieron suyos los barrios y calles de la ciudad, como si fueran unos vecinos más ${ }^{11}$. Puede parecer algo anecdótico la mención a estos animales, a los que incluso les dedicó un soneto, en el cual reconoce su labor, contraponiéndola a la desidia de los propios

\footnotetext{
$7 \quad$ Véase: Correa Ramón, A., «Introducción», pp. 52-53.

8 Correa Ramón, A., «Introducción», p. 56; Correa Ramón, A., «La experiencia», p. 9.

9 De Zayas, A., A orillas, pp. 27-28.

10 De Zayas, A., A orillas, pp. 29-31.

11 De Zayas, A., A orillas, pp. 38-39. 
constantinopolitanos:

Mientras el mozo inútil se consagra al reposo contemplando el Ocaso por las costas y valles, él de Estambul recorre las tortuosas calles, de la higiene otomana polizonte celoso ${ }^{12}$.

Una de las claves de la visión de Antonio de Zayas sobre Estambul y sus habitantes reside en la cuestión religiosa. Para el duque de Amalfi, la única fuente de verdadera cultura es el cristianismo, de ahí que todo lo que sea ajeno a los valores morales emanados de éste, pertenece a la barbarie ${ }^{13}$. No es de extrañar que juegue con la dicotomía entre el próspero barrio de Pera, en el que la impronta europea es más que evidente, y el resto de Estambul, sumido en la apatía, cuyo espíritu simboliza el Gran Bazar ${ }^{14}$. Un estereotipo que sobrevuela muchos de sus versos, pudiendo servir de ejemplo el soneto titulado Tarde de viernes, en el que hace referencia a un grupo de turcas sentada sobre las ruinas de los edificios genoveses, ejemplo de cómo el alma oriental que se había apoderado de las tierras de Anatolia y Tracia ${ }^{15}$.

Cuando Antonio de Zayas llegó a la capital otomana, Turquía se hallaba en un período que, en un reciente estudio, F. Veiga llamó «Estado de excepción ilustrado ${ }^{16}$, correspondiente al reinado del sultán Abdülhamid II (1877-1909), marcado por las guerras con Rusia (1877-1878) y la ya mencionada con Grecia, en 1897. Dejando las cuestiones bélicas a un lado, su gobierno se caracterizó por ser el primero en promulgar una Constitución, el kanunu esâsî, por la cual se instauraba en el Imperio otomano un sistema parlamentario bicameral, aunque el sistema democrático estaba lejos de ser una realidad, entre los años 18771878. Las cámaras, convertidas en Asamblea Nacional, serán quienes depongan al propio Abdülhamid II, basándose en una fatwa en la que se acusaba al sultán de no cumplir con los preceptos de la ley islámica.

El año de llegada de De Zayas a Estambul no fue sólo complejo en la política internacional, sino también en la interna. El gobierno de la Sublime Puerta intentó disolver el movimiento de la Joven Turquía en 1897, para evitar

$12 \quad$ De Zayas, A., Joyeles, p. 77.

13 De Zayas, A., A orillas, p. 29.

14 De Zayas, A., A orillas, pp. 108-109.

15 De Zayas, A., Joyeles, p. 63.

16 Veiga, F. (2006), El turco. Diez siglos a las puertas de Europa, Barcelona: Debate, p. 363. 
cualquier cuestionamiento del poder del sultán, como ya había sucedido con el frustrado golpe de Estado protagonizado por esta organización ${ }^{17}$. El clima provocado por la persecución de este grupo político quedó reflejado en el soneto Narghilé, dejando constancia de la red de espionaje y delación tejida en torno a los cafés; de las suspicacias hacia cualquier elemento que pudiera parecer sospechoso ${ }^{18}$.

Es un reinado clave, en tanto que en Turquía trataron de introducir elementos de gobierno propios de los Estados absolutistas europeos de los siglos XVIII y comienzos del XIX. Junto a esta característica, otras de las patas sobre la que se sustentó el reinado de Abdülhamid II fue el panislamismo, acentuando su papel como califa, es decir, como líder religioso, un modo de acallar cualquier tipo de voces discordantes, sobre todo entre los árabes, buscando enfatizar los lazos religiosos comunes, por encima de las diferencias étnicas y culturales existentes entre los diversos pueblos que conformaban el mosaico que era el Imperio otomano. Por esta razón, en las cancillerías europeas se acusaría a este sultán de oscurantista y fanático ${ }^{19}$, imagen acrecentada por la dura represión con la que castigó las revueltas armenias y cretenses ${ }^{20}$.

El fanatismo que De Zayas achaca a los griegos ha de ser entendido como una reacción a ese panislamismo puesto en marcha desde el gobierno otomano. La ortodoxia se erige en una barrera protectora de la minoría griega frente a los musulmanes; un medio de conservar su identidad. Lo que mueve a los griegos es más el odio a los turcos que una cuestión de fe, según relata el poeta y diplomático español. La descripción que hace en $A$ orillas... de la Iglesia Griega Ortodoxa está mediatizada por el conflicto entre el Papa León XIII (1878-1903) y sus colegas orientales, en especial con Antimo VII (18271897), sobre todo como consecuencia de la encíclica Praeclara gratulationis de 1894 por la que invitaba a todos los cismáticos orientales a unirse a la Iglesia de Roma y respondida por los ortodoxos un año más tarde con una reafirmación de sus posturas. Esta actitud llevó al pontífice a promulgar en 1896 otra encíclica, la Satis cogitum, en torno a la unidad de la Iglesia y en definitiva, un alegato en favor de la infalibilidad papal («aprobada» en 1870, en el marco de

\section{$17 \quad$ Veiga, F., El turco, p. 375.}

18 De Zayas, A., Joyeles, p. 79.

19 Uno de los capítulos de la obra de A. de Zayas, el XV, lleva precisamente como título «El fanatismo», en el que describe las creencias religiosas llevadas al extremo por parte de los musulmanes [véase: De Zayas, A., A orillas, pp. 235-250].

20 Sobre la figura de este sultán, véase: Deny, J. (1986), "'Abd al-Hamid II», Encyclopaedia of Islam (2 ${ }^{\text {nd }}$ edition), Leiden: E. J. Brill, vol. 1, pp. 63-65. 
la construcción del Estado-nación italiano) frente a las reticencias orientales ${ }^{21}$. Es en este contexto en el cual, De Zayas, acusa a los griegos de las «clases acomodadas» de tibieza religiosa, rayana en el escepticismo y la indiferencia ${ }^{22}$.

Teniendo en cuenta la, en palabras de Amelina Correa, «involución» ${ }^{23}$ experimentada por Antonio de Zayas, adoptando una postura reaccionaria, proceso cuya culminación sería la identificación con la retórica y los valores del nacionalcatolicismo impuesto en España por la dictadura del general Franco (1936/1939-1975), algunas de las críticas que hace a los griegos resultan una incoherencia. Especialmente cuando afirma que la patria la equiparan a la Iglesia y la Religión; que no invocan la tierra en la que viven porque no quieren ser confundidos con los turcos musulmanes, de ahí que para crear unos vínculos identitarios echen mano a las creencias comunes. Muchos griegos colaboraban con los turcos desde el momento mismo de la conquista ${ }^{24}$, incorporados al ejército, resaltando cómo pretendían hacerse con dos de las más destacadas condecoraciones militares otomanas: la Medjidié y la Osmanie ${ }^{25}$. La religión no es algo espiritual, sino «el pasaporte que les asegura la libertad» ${ }^{26}$.

Establece una contraposición entre el catolicismo militante y la ortodoxia, en base al odio que sienten éstos por los cristianos orientales, a quienes considera, en línea con el discurso romano imperante, «hijos díscolos de la Santa Iglesia Romana ${ }^{27}$, mientras que los griegos motejan a los latinos de falsos cristianos ${ }^{28}$. El sentimiento anti-latino y anti-occidental entre los griegos tendría como origen el cisma de 1054, fomentado por los emperadores y los sucesivos patriarcas ${ }^{29}$. Denuncia la pompa y el boato de las celebraciones litúrgicas ortodoxas, que en modo alguno son una muestra de la rectitud del

21 Véase: Meyer, J. (2006), La gran controversia. Las Iglesias católica y ortodoxa de los orígenes a nuestros días, Barcelona: Tusquets, pp. 317-319; «Pope Leo XIII» en The Catholic Encyclopedia, disponible en: http://www.newadvent.org/ cathen/09169a.htm [última consulta: 29/12/2015].

22 De Zayas, A., A orillas, p. 47.

23 Véase: Correa Ramón, A., «Introducción», pp. 80-81; Nebot Nebot, J. V., Antonio de Zayas, p. 14.

24 De Zayas, A., A orillas, p. 46.

25 De Zayas, A., A orillas, p. 44.

26 De Zayas, A., A orillas, p. 47 y 49.

27 De Zayas, A., A orillas, p. 47.

28 De Zayas, A., A orillas, p 114.

29 Véase: Lounghis, T. C. (2010), Byzantium in the Eastern Mediterranean: Safeguarding East Roman Identity (407-1204), Nicosia: Cyprus Research Centre, p. 32 . 
dogma. El reverso de esas misas se halla en la pobreza del templo de Fanar, donde se encuentra el núcleo de la Iglesia ortodoxa griega ${ }^{30}$, con la grandeza de la basílica de San Pedro del Vaticano ${ }^{31}$. El otro centro de la Ortodoxia se halla en la isla de Halki, en la que está el seminario de la Iglesia griega, en el monasterio de San Jorge, famoso por su «opulenta biblioteca» ${ }^{32}$, cerrado desde que en 1971 el gobierno de Ankara lo clausurara de manera arbitraria, sin que en la actualidad haya ningún cambio.

Estas divergencias dan pie al diplomático y poeta español para establecer las principales diferencias entre el patriarca de Constantinopla y el Papa de Roma. El primero carecía de cualquier tipo de influencia; una falta de relevancia que no se debía a la falta de libertad, ya que los cristianos griegos gozaban de una amplísima autonomía. Llega a afirmar que preferiría la vigilancia a la que está sometido el pontífice ortodoxo en comparación a la situación en la que vivía León XIII. Constantino V (1897-1901) gozaba de la protección de las potencias occidentales, que atenuaba las presiones de los musulmanes, mientras que el pontífice romano estaba a merced de los gobiernos italianos, sin ningún apoyo exterior, máxime después de la desaparición de los Estados Pontificios tras la Reunificación italiana ${ }^{33}$.

En la lógica seguida por De Zayas, todo se resume en el enfrentamiento entre quien considera el sucesor de Focio (858-867 y 877-886) y el de San Pedro $^{34}$. Es decir, unos patriarcas cuya autoridad emana de un patriarca cismático frente al sucesor del apóstol elegido, según la tradición evangélica, por Jesús como cabeza de la comunidad tras su muerte (Mt 16, 18). Esto equivalía a negar que la sede de Constantinopla estuviera dentro de la tradición apostólica en la

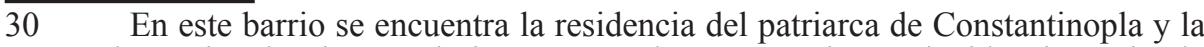
Escuela Nacional Griega. Asimismo, se produce una curiosa coincidencia, teniendo en cuenta los acontecimientos históricos. En Fanar se guardaba el alfanje de Mehmet II (1444-1445, 1451-1481), el conquistador de la capital bizantina en mayo de 1453. Al mismo tiempo, fue el lugar de nacimiento de la Revolución griega que concluyó con la proclamación de Grecia como Estado independiente en 1830 [De Zayas, A., $A$ orillas, pp. 111-112]. En dos sonetos, De Zayas alude a ambos acontecimientos: 1-. El Cuerno de Oro: alude al alfanje de con el que Mehmet «rindió la Fortuna» [De Zayas, A., Joyeles, p. 58]; 2-. Fanairiki: hace referencia a los héroes de la guerra de independencia de Grecia y a la ayuda británica [De Zayas, A., Joyeles, p. 57].

De Zayas, A., A orillas, p. 114.

32 De Zayas, A., A orillas, p. 286.

33 De Zayas, A., A orillas, pp. 114-115. En su defensa a ultranza de la institución papal, llama a los Saboya usurpadores.

34 De Zayas, A., A orillas, p. 117. 
que se basaba la autoridad de los obispos ${ }^{35}$ y por tanto, carente de cualquier legitimidad. Es curioso que el mencionado sea Focio, quien condujo a un primer cisma, y no Miguel I Cerulario (1043-1058), con quien se consumó el segundo y definitivo.

El patriarca del siglo IX concita la mayor animadversión por parte de De Zayas, situándolo entre los grandes heresiarcas, al mismo nivel que Arrio $(† 336)$ y Martín Lutero ( $\uparrow 1546)$, bestias negras para la Iglesia de Roma en distintos momentos. Al igual que ellos, rompió con la disciplina romana, basándose en la «adulteración» del Símbolo de Nicea que hicieron en Occidente con la incorporación del filioque. Por tanto, según los cristianos occidentales, el Espíritu Santo procedía tanto del Hijo como del Padre ${ }^{36}$. Para el papa Juan VIII (872-882) y sus seguidores, rechazar esta interpretación, colocaba a los orientales muy próximos al arrianismo. Focio comparte con ellos una ambición desmedida que los llevó a levantarse contra el «Vicario de Jesucristo». La separación de Roma supuso el inicio del fin de la Romania, ya que los griegos se granjearon la enemistad de los demás cristianos de Occidente, quienes vieron con «frialdad» las humillaciones que sufrieron a manos de los turcos que expugnaron «valerosa y cruelmente los muros de Constantinopla» ${ }^{37}$.

La diversidad del cristianismo oriental es, según De Zayas, fruto del gusto griego por la discusión. De los debates eruditos habrían surgido todas las herejías y cismas que dividieron la Cristiandad, debilitándola. Lo más grave de todo era que eran unas diatribas vacías en torno a las formas del rito. Llama a los teólogos orientales sofistas y liga su origen a la decadencia del Imperio bizantino. Eran estas nimiedades las que contribuían a «entibiar la fe» ${ }^{38}$, acusación que ya lanzara contra la elite griega de Constantinopla. Ese conglomerado que formaban y forman las Iglesias orientales, con sus

$35 \quad$ Sobre la «tradición apostólica», véase: Peters, F. E. (2007), Los hijos de Abraham. Judaísmo, Cristianismo, Islam, Barcelona: Laertes, p. 97.

36 Sobre el filioque, véase: «Filioque», $O D B$, vol. 2, pp. 785-786. Aunque en este caso se haya hecho mención a las cuestiones teológicas que provocaron el cisma, éstas sólo fueron la excusa para manifestar las tensiones entre Constantinopla y el Occidente latino. De hecho, el término en cuestión venía empleándose desde el Tercer Concilio de Toledo (589). En primer lugar, por la cuestión del Ilírico, un región en pugna entre ambas esferas, acrecentada por las evangelizaciones de los eslavos de la Gran Moravia. A ello habría que sumar la situación en la Península Itálica, con la intervención de los francos en socorro del Papado frente a los lombardos, obviando así a los bizantinos. Pero sobre todo, la coronación de un nuevo emperador en Occidente, en base a un documento falso: la Donación de Constantino.

37 De Zayas, A., A orillas, p. 118.

38 De Zayas, A., A orillas, p. 118. 
distintas jurisdicciones, favorecidas por el sistema de millet $^{39}$, les resta fuerza por su falta de acuerdo y la carencia de una cabeza rectora ${ }^{40}$. Es el principio de unidad y mando único que lleva a De Zayas, por ejemplo, a despreciar el sistema republicano francés y añorar los «viejos buenos tiempos» en los que la institución monárquica era la norma en Europa ${ }^{41} \mathrm{o}$ a sumarse a la revuelta contra el gobierno legítimo de la II República en 1936. El horror que siente el diplomático español por las querellas que, irremediablemente -según su visión-, conducen a la división, lo lleva a hablar de los «siglos lóbregos» en los que se produjeron las discusiones teológicas y jurídicas, de las que fueron testigos los Caballos de Lysipo $^{42}$, conjunto escultórico que en su origen estaba en Constantinopla, hasta 1204, cuando fue llevado a Venecia, donde A. de Zayas lo contempló en su viaje hacia Estambul.

El Bósforo representa para De Zayas una muralla inexpugnable que había sido franqueada en múltiples ocasiones, desde la guerra de Troya hasta la Guerra de Crimea (1853-1856), presentada como una guerra sagrada en la que «la flota británica y las águilas del Segundo Imperio defendieron los derechos latinos sobre los Lugares Santos contra los presuntos derechos de los cismáticos rusos $\rangle^{43}$. A pesar de todas las luchas, jamás se logró la unidad entre Europa y Asia, algo que sí habían conseguido los turcos. Esa división existente tenía un efecto positivo: «el régimen teocrático» propio del Oriente no llegó a implantarse en el suelo europeo, pero al mismo tiempo, regímenes moralmente superiores, como la democracia de Atenas o las leyes romanas, no arraigaron en Siria ni Fenicia. La Iglesia tampoco pudo imponer un dogma único entre todos los cristianos. La perfidia y suspicacias de los prelados orientales dificultaron enormemente la labor pontificia ${ }^{44}$.

La visión de Bizancio que aporta De Zayas está muy mediatizada por lo que él considera decadente frente a lo nuevo; el vicio frente a la virtud, con un fuerte trasfondo religioso. De ahí que señale la caída de los Paleólogos y el

39 Véase: Ursinus, M. O. H., (1993), «Millet», Encyclopaedia of Islam (2 ${ }^{\text {nd }}$ edition), Leiden-Nueva York: E. J. Brill, vol. 7, pp. 61-64.

40 De Zayas, A., A orillas, pp. 119-120.

41 Véanse los comentarios que hace sobre París y la III República, con motivo de su estancia de camino hacia Constantinopla. Puede servir de muestra la siguiente cita: «No existe en toda la extensión del planeta pueblo alguno menos demócrata que el pueblo francés, ni más enemigo de la igualdad que predica» [De Zayas, A., A orillas, p. 22].

42 De Zayas, A., Joyeles, p. 28.

43 De Zayas, A., A orillas, pp. 300-301.

44 De Zayas, A., A orillas, pp. 302-303. 
Imperio en manos de los turcos como un castigo por los vicios de esta dinastía ${ }^{45}$. Se trataba de la sangre nueva que venía a regenerar -término éste muy en boga en la España de finales del XIX y principios del xx- un Estado corrupto. A pesar de esta imagen negativa, es capaz de escribir versos de gran belleza y fuerza sobre el final del Imperio como este:

por las aguas arrastra el armiño sangriento la no vengada sombra del postrer Paleólogo ${ }^{46}$.

Su idea del Imperio romano de Oriente queda enmarcada en el (lógico para su época) tópico, que Edward Gibbon plasmó en The History of the Decline and Fall of the Roman Empire (1776-1788), según el cual, no habría nada de valor en la Historia de Bizancio, en contraposición a la Imperio romano clásico.

Bizancio es el lugar en que se unen Grecia y Roma, la herencia del paganismo con el cristianismo, de la mano de Constantino (ca. 306-327). En el Imperio, el ciudadano era el centro en torno al cual giraba todo, por lo que lo público y espacios en los que se desarrollaba la vida ciudadana, eran fundamentales, de ahí que se decorara y embelleciera el Foro para mayor gloria de la ciudad. Pero la corrupción de las costumbres en Bizancio hacía que la muchedumbre fuera incapaz de gobernarse a sí misma, con el Hipódromo como epítome de la degeneración del pueblo ${ }^{47}$, en contraposición a las democracias aristocráticas de la Grecia clásica.

De Zayas, no obstante, destaca el hecho de que Constantinopla fuera la capital del Imperio cristiano, un carácter que a priori podría considerarse positivo, pero que en realidad tiene un reverso negativo: convertirse en la cabeza de la Cristiandad rivalizando con Roma. Una enemistad que se ahonda por las «suntuosidades» de Valente y Teodosio ${ }^{48}$, en referencia al «lujo asiático» con el que se describe la corte constantinopolitana frente a la austeridad romana. La mención explícita a estos dos emperadores, no puede ser casual. Valente (364378) fue el último emperador arriano; su muerte en la batalla de Adrianópolis (agosto de 378) frente a los godos -también arrianos- se vio como un castigo de Dios por haberse alejado de la ortodoxia nicena ${ }^{49}$. El Teodosio al que alude

\begin{tabular}{ll}
\hline 45 & De Zayas, A., A orillas, pp. 149-150. \\
46 & De Zayas, A., Joyeles, p. 35. \\
47 & De Zayas, A., A orillas, pp. 162-166. \\
48 & De Zayas, A., A orillas, p. 156. \\
49 & Treadgold, W. (1995) Byzantium and its Army (284-1081), Stanford: Stanford \\
\\
University Press, p. 11; Fernández Ubiña, J. (1997), «Conflicto arriano y compromiso
\end{tabular} 
De Zayas, es Teodosio II (402-450) -para Teodosio I (379-395), por su origen hispano, hubiera tenido palabras elogiosas-, un emperador que, en palabras del bizantinista Charles Diehl: «Era un emperador concienzudo y mediocre, bueno quizás para una época de paz, pero del todo insuficiente para el tiempo turbulento en que vivió ${ }^{50}$. Fue durante su reinado cuando estalló la herejía del patriarca de Constantinopla Nestorio (428-431), también en torno a la divinidad de Cristo, por la que este emperador sintió ciertas simpatías en un primer momento, doctrina que sería finalmente condenada en el Tercer Concilio Ecuménico de Éfeso (431).

La última gloria que le reconoce al Imperio bizantino es la militar y jurídica que alcanzó en tiempos de Justiniano (527-565), con las figuras de los generales Belisario y Narsés en primer plano. El otro hito del esplendor de este reinado lo representa Santa Sofía, edificio hacia el que Antonio de Zayas expresa sentimientos encontrados. Le extraña que aún se conserve el espíritu cristiano a pesar de todas las transformaciones a las que ha sido sometida, que describe como una «herida de alfanje» ${ }^{51}$. Pero no sólo en el aspecto exterior del templo, sino también en el interior: en Santa Sofía se guarda y venera el «mugriento trapo» sobre el que, según la tradición islámica, oraba el Profeta Muhammad $^{52}$. El templo se mueve entre el origen pagano de los materiales con los que se construyó y el espíritu cristiano de su arquitectura. Este último aspecto, también es elogiado en el soneto Santa Sofía, en el que a su estatismo hierático, que le confiere un aspecto atemporal ${ }^{53}$. De nuevo, es el fanatismo islámico el que rompe con la armonía del edificio. Señala que carece de esbeltez y austeridad, por culpa de los alminares y otros anexos posteriores, que no son más que «afeites en rostro de anciana matrona» ${ }^{54}$. Y sin embargo, De Zayas tiene que reconocer el profundo impacto que le produce ver el interior de Santa Sofía, destacando los juegos de luces, que lleva a contraponer el pastiche exterior con la espiritualidad interior ${ }^{55}$. Manifiesta el diplomático su orgullo de

político en el episcopado latino del Bajo Imperio» en Moschos Morfakidis - Minerva Alganza Roldán (eds.), La religión en el mundo griego. De la Antigüedad a la Grecia Moderna. Granada: Athos-Pérgamos, pp. 221-248, espec. 244-245.

50 Diehl, Ch. (1948), Figures bizantines, 2 vols. París: Armand Colins (10 edición), vol. 1, p. 30.

51 Véase el soneto que le dedica a Santa Sofía en Joyeles, p. 103.

52 De Zayas, A., A orillas, p. 190.

53 Véase: De Zayas, A., Joyeles, p. 103.

54 De Zayas, A., A orillas, p. 193.

55 De Zayas, A., A orillas, pp. 194-195. 
ser cristiano, en tanto que entendía que sólo el espíritu vigoroso del cristianismo podía realizar una construcción semejante ${ }^{56}$, y el desprecio que le provocan aquéllos que no luchan por recobrar ese lugar ${ }^{57}$, en referencia a las políticas pro-turcas de algunas cancillerías europeas.

A partir de este momento culmen, Antonio de Zayas se desliza hacia una lista de personajes que marcaron, según la óptica de su época, las páginas más negras de la Historia de Bizancio. Su particular catálogo de la infamia lo abre con Teodora, a la que compara con la mítica Semíramis de Babilonia. Pero es sobre todo contra la emperatriz Irene (797-802) contra la que dirige sus dardos, acusándola de haber cometido, para saciar su ambición, más crímenes que Focas (602-610) ${ }^{58}$-convertido en paradigma de emperador sanguinario y vengativo, al que sólo podría salvar, a ojos del diplomático español, el reconocimiento por parte del papa Gregorio Magno (590-604)-. Liga a esta emperatriz con la isla de Prinkipo, escenario en el que se ejecutaron injusticias y se evidenció la tiranía bizantina; en uno de los monasterios de esta isla, fue recluida Irene, tras ser destronada por Nicéforo I (802-811), ahora descrita como una Medea medieval, ya que ambas habrían matado a sus hijos ${ }^{59}$. Se trata de una imagen en exceso negativa de quien pusiera fin a la primera oleada iconoclasta, pero a quien desde Occidente no se le perdonaría el rechazo a las pretensiones imperiales de Carlomagno ${ }^{60}$. Bizantinistas de la talla de Ch. Diehl habrían ayudado a extender la leyenda negra en torno a esta soberana ${ }^{61}$, de la que De Zayas sólo era un eslabón más.

Tampoco León III (717-741) habría de librase de las invectivas del diplomático español, quizás con más motivo que Irene, ya que fue su política religiosa la que condujo al estallido iconoclasta. Lo llamará usurpador y cabeza de la «envilecida y ciega cohorte de los iconoclastas» ${ }^{62}$, deslegitimándolo como emperador, teniendo en cuenta que en el año 722, lanzó una campaña contra el papa Gregorio II (715-731) con el fin de devolverlo a la obediencia

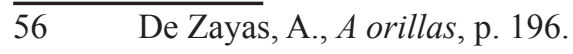

57 De Zayas, A. A orillas, p. 195. Este sentimiento irredentista, está asimismo presente en el final del soneto ya citado: «y las justas venganzas, a los cielos confía»

58 De Zayas, A., A orillas, p. 157.

59 De Zayas, A., A orillas, p. 290.

60 Para una nueva visión sobre la emperatriz Irene, véase: Herrin, J. (2002), Mujeres en la púrpura. Irene, Eufrosine y Teodora. Soberanas del medievo bizantino, Madrid: Taurus, pp. 79-173.

61 Diehl, Ch., Figures, pp. 77-109.

62 De Zayas, A., A orillas, p. 209. 
de Constantinopla ${ }^{63}$, en un episodio más del intervencionismo bizantino en Occidente; una injerencia de un poder terrenal en los asuntos espirituales, competencia exclusiva del Papado.

Pero son las querellas teológicas, como se ha señalado en repetidas ocasiones a lo largo de las páginas precedentes, las que marcan la decadencia de Bizancio, en tanto que propiciaron la separación de las dos Iglesias. No es de extrañar que sea señalado de nuevo Focio, «rebelde y concupiscente», como uno de los principales culpables, a cuya figura contrapone la de Ignacio (827858 y 867-877), a quien llama «mártir», el rival de Focio por el solio patriarcal de Constantinopla. Un santo, Ignacio, proclive al entendimiento con la sede romana, frente a un heresiarca, que presenta De Zayas atrapado por los pecados de la carne y la soberbia.

Un Imperio por un lado encajonado entre el Islam $^{64}$ y los eslavos, incultos e idólatras, y por otro, apresado entre los vicios propios y la ambición extranjera ${ }^{65}$. Esta última afirmación no le impide presentar a los cruzados de 1204 como los paladines del cristianismo, un revulsivo para el comercio oriental y la industria ${ }^{66}$. Para el diplomático y poeta español, Levante había quedado vacío de población cristiana, hasta la llegada de los cruzados, dibujados como paradigma de la tolerancia frente a los «fanáticos sectarios de Mahoma» ${ }^{67}$, imagen que contrasta con lo expuesto por Steven Runciman. Según el historiador británico, los cristianos de Levante gozaban de una situación de estabilidad cuando llegaron los cruzados, gracias a la indulgencia de las autoridades musulmanas y la protección dispensada por el emperador de Constantinopla ${ }^{68}$. La ambición de los latinos habría encontrado en las «criminales concupiscencias» de los Isaurios, Paleólogos y Cantacuzenos ${ }^{69}$.

Preocupa más el hereje que el infiel. Por esta razón, De Zayas alaba la dominación andalusí de Creta, contraponiéndola a las calamidades que arrasaron la isla como consecuencia de su reincorporación a un Imperio en

$63 \quad$ Véase: Lounghis, T. C., Byzantium, p. 41.

64 Es lógico que presente al «iluso discípulo de Focio», es decir, a los griegos ortodoxos, con un tespik, la sarta de cuentas similar al rosario occidental, típico de los turcos. Véase: De Zayas, A., Joyeles, p. 80.

65 De Zayas, A., A orillas, p. 157.

66 De Zayas, A., A orillas, p. 82.

67 De Zayas, A., A orillas, p. 323.

68 Runciman, S. (1956), Historia de las Cruzadas, 3 vols., Madrid: Revista de Occidente, vol. 1: La Primera Cruzada y la fundación del Reino de Jerusalén, p. 37. De Zayas, A., A orillas, p. 129. 
franca decadencia ${ }^{70}$. Esta imagen favorable a al-Andalusi podría parecer un contrasentido en la obra de un autor marcadamente nacionalista y católico. No obstante, en la segunda mitad del siglo XIX, comenzó un proceso de integración de lo andalusí en la conformación de la identidad nacional española, al presentar un fondo «racial» común a los cristianos y musulmanes de la Península Ibérica $^{71}$. Por esta razón, no es de extrañar que califique como «desbarajuste» la administración otomana de Creta en manos de unos gobernadores corruptos que se comportaban como los pretores romanos: más preocupados por su enriquecimiento personal que por el bienestar de los cretenses ${ }^{72}$.

Los Paleólogos representan la culminación de la degeneración de Bizancio, si bien reconoce que hubo una suerte de resarcimiento con el último Constantino, a quien comprara con Boabdil, el último emir de la Granada nazarí, poniendo en boca del bizantino unas palabras similares a las que la tradición española adjudica al musulmán: «Aquí fue Bizancio» ${ }^{73}$. No obstante, reconoce la liberalidad de los emperadores Paleólogos, y cita la fundación del «convento de Panaguía [sic]», en Halki, por Juan Paleólogo y María Comneno ${ }^{74}$, es decir, Juan VIII Paleólogo (1425-1448) y su esposa María, hija de Alejo IV Comneno (1416-1429), del Imperio de Trebizonda. El rencor que muestra De Zayas no sólo por esta dinastía, sino también por la familia Cantacuzeno, que compartieron el poder imperial en el último siglo de Bizancio, se debe principalmente a la negativa de Juan VI Cantacuzeno (1347-1354) o Manuel II Paleólogo (1391-1425) a la unión de las Iglesias como requisito previo al envío de ayuda militar por parte de los occidentales. Este aspecto de la política religiosa ha sido el que más interés ha suscitado entre quienes se dedicaron al estudio del período Bizantino final.

Por el contrario, Mehmet II no es presentado como un déspota sanguinario sino como un gobernante pragmático que supo valerse de los vencidos, mucho mejor formados que los turcos, pero sobre todo por haber impedido la unión de las Iglesias al permitir la supervivencia del Patriarcado,

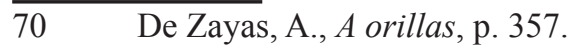

71 Sobre esta cuestión, véase: García Sanjuán, A. (2012), «Al-Andalus en la historiografía del nacionalismo españolista (siglos XIX-XXI). Entre la Reconquista y la España musulmana», en Diego Melo Carrasco - Francisco Vidal Castro (eds.), A 1300 años de la conquista de al-Andalus (711-2011). Historia, cultura y legado del Islam en la Península Ibérica, Coquimbo-Chile: Altazor, pp. 65-104, espec. 80

72 De Zayas, A., A orillas, p. 364

73 De Zayas, A., A orillas, p. 157.

74 De Zayas, A., A orillas, p. 287. 
ya que mantenía débil al Papado y aseguraba la pervivencia del Islam ${ }^{75}$. Si bien reconoce el diplomático español algunas acciones, que él achaca -cómo noal « fanatismo de los musulmanes », como la destrucción del templo de San Miguel en 1452 y la construcción con sus restos de la Rumeli Hissar (i.e. Torre de Rumelia ${ }^{76}$ ), a cuyos pies se halla un cementerio musulmán en el que reposan los restos de los primeros turcos que invadieron Europa, hecho por el cual es un lugar muy venerado ${ }^{77}$.

El retrato que Antonio de Zayas hace de los griegos que encontró durante su estancia en Estambul, carece de cualquier simpatía hacia ellos. Baste para justificar esta apreciación, el hecho de que cite en $A$ orillas... que la mayoría de los presos en las cárceles otomanas eran griegos, una prueba fehaciente de su degeneración moral ${ }^{78}$. Su frustración con respecto a los griegos nace de comprobar que no son los herederos de Sócrates ni de las mujeres que sirvieron como modelos que sirvieron para tallar las estatuas. Los griegos de finales de los siglos XIX poco o nada tenían que ver con la imagen idealizada que de ellos habían construido, entre otros, los escritores románticos. Esa exaltación de la Grecia Antigua no deja de ser una contradicción en la pluma de un escritor que, como era el caso de A. de Zayas, desconocía tanto el griego moderno como el clásico ${ }^{79}$. La base de su éxito era la especulación y la ductilidad más que el talento; no eran inteligentes sino listos y astutos ${ }^{80}$. Ello no le impide afirmar superioridad cultural de los griegos llevó a la conquista moral de los turcos ${ }^{81}$.

75 De Zayas, A., A orillas, pp. 325-326.

76 El término Rumelia era el empleado por los turcos para hacer referencia a aquellas provincias que habían pertenecido al Imperio bizantino en la Península Balcánica. La voz turca procede de la palabra usada por los propios bizantinos para nombrar a su Estado: Romania. Véase: Inalcik, H (1995), «Rûmeli», Encyclopedia of Islam ( $2^{\text {nd }}$ edition), Leiden: E. J. Brill, vol. 8, pp. 607-611.

77 De Zayas, A., A orillas, pp. 309-310. Sobre la Rumeli Hissar, véase: Kreiser, K. (1995), «Rûmeli Hissârî», Encyclopedia of Islam (2 ${ }^{\text {nd }}$ edition), Leiden: E. J. Brill, vol. 8, pp. 611-612.

78

79 En una carta que le envió el escritor Juan Valera ( $†$ 1905), con el que mantenía una relación amistosa y compartía carrera diplomática, fechada en Madrid, 17 de julio de 1897, le recomienda que «aprenda la lengua griega moderna, como lengua viva, lo cual, en mi sentir, es el modo de aprender el griego antiguo y de leer pronto y corrientemente los grandes escritores clásicos», Valera, J. (2007), Correspondencia, edición de Leonardo Romero Tobar (dir.), $\mathrm{M}^{\mathrm{a}}$ Ẩngeles Ezma Gil y Enrique Serrano Asenjo, 8 vols., Madrid: Castalia, vol. 6, Años 1895-1899, pp. 288-289

80 De Zayas, A., A orillas, pp. 43-44.

81 De Zayas, A., A orillas, p. 80. 
Y aunque no tenían nada que ver con los griegos del período Clásico, De Zayas señala cómo éstos miraban al resto de las naciones europeas con cierto desprecio, declarándose sus herederos directos. Un desdén que contrasta con la adopción de modos y modas europeas, una capa superficial bajo la cual se oculta un fondo netamente oriental ${ }^{82}$. Los cafés constantinopolitano servían como observatorio, desde el que el diplomático español fue testigo de lo que consideraba la ordinariez de las damas vestidas a la europea y los señores tocados con el fez, de esos griegos de rostro cetrino, animado y alegre ${ }^{83}$. Una vulgaridad que queda reflejado en el entretenimiento por antonomasia: el karogueutz [sic. por karaguiosis], el teatro de sombras que De Zayas identifica como un «Polichinela oriental», señalando los juegos de palabras y los consiguientes equívocos que tenían como tema principal el harén ${ }^{84}$.

Además de poner de manifiesto la tibieza religiosa de la burguesía greco-turca, otra de las características que destaca de ellos es el sentimiento panhelénico que lleva a los griegos a soñar con la restauración del Imperio de Oriente. Unas pretensiones que arrancan al diplomático español una reflexión no exenta de cierta ironía, cuando apunta que «aspiran, en fin, a conquistar el papel airoso que desempeñaron cuatro siglos antes de la venida del Mesías ${ }^{85}$. A la luz de esta cita, se comprueba cómo el pasado bizantino es completamente ignorado.

Este orgullo nacional de un pueblo que no tiene una nación propia basado en un pasado idealizado en exceso, como estos griegos que vivían en el Imperio otomano, es para De Zayas una fatuidad ridícula, puesto que no tienen cualidades positivas ${ }^{86}$. Difícilmente se les podía distinguir de los turcos en cuanto a costumbres y menciona la del aperitivo con mastica y raki o, la que el diplomático considera la más turca de todas, los dulces de cuchara $^{87}$. Añade asimismo el gusto (desaforado) por los juegos de cartas, especialmente el poker, hasta el punto de convertirlo en la quinta plaga de Constantinopla, junto a la pesti, cani, fochi e dragomani, es decir, junto a las epidemias, perros, fuego y los intérpretes, que, generalmente solían ser griegos al servicio de la Sublime Puerta. El juego no era un mero entretenimiento, sino un negocio especulativo

\begin{tabular}{ll}
\hline 82 & De Zayas, A., A orillas, p. 50. \\
83 & De Zayas, A., A orillas, p. 59. \\
84 & De Zayas, A., A orillas, p. 130; Joyeles, p. 96. \\
85 & De Zayas, A., A orillas, p. 293. \\
86 & De Zayas, A., A orillas, p. 294. \\
87 & De Zayas, A., A orillas, pp. 294-295.
\end{tabular}


para muchos hombres y mujeres que derrochaban y a veces ganaban enormes fortunas encima del tapete verde de las mesas de juego ${ }^{88}$.

Lo que parece despertar una cierta conmiseración en De Zayas era la afirmación de estos burgueses de que conseguirían su objetivo «Sin fiar en latinos ni en eslavos» ${ }^{89}$, es decir, sin la ayuda ni de las potencias europeas ni de Rusia. Una sentencia que podría parecer un ejercicio de alarde nacionalista, no era más que la constatación de qué podían esperar de esas potencias. La Guerra de los Treinta Días supuso un choque con las complejas alianzas que entretejían la política internacional de finales del xIx. Cuando estalló la guerra entre Grecia y Turquía, Francia se apresuró a asegurarle a Rusia que una posible intervención de Austria-Hungría no llevaría a un conflicto generalizado ${ }^{90}$.

El sentimiento irredentista no era el monopolio único de los griegos que vivían en Turquía sino que era común a todos los griegos. El diplomático español califica de insensato el deseo de restaurar el Imperio bizantino ellos solos, embarcándose en luchas suicidas contra un Imperio otomano que, si bien estaba herido de muerte en modo alguno daba muestras de estar acabado ${ }^{91}$. Frente a la pasividad de las demás potencias europeas ante las masacres de armenios que estaban teniendo lugar en Estambul y otras ciudades del Imperio entre el 30 de septiembre de 1895 y agosto de $1896^{92}$ o la dura represión con la que se estaba sometiendo la enésima revuelta cretense. Según relata De Zayas, testigo privilegiado de los hechos, fue el gobierno de Atenas el que movió ficha, con el envío de dos acorazados y 2.000 soldados de infantería al mando del coronel $\operatorname{Vassos}^{93}$, que presentó la intervención griega ordenada por el rey

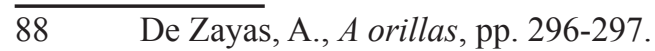

89 De Zayas, A., A orillas, p. 294.

90 Véase: Clark, C. (2014), Sonámbulos. Cómo Europa fue a la guerra en 1914, Barcelona: Galaxia Gutenberg, p. 340.

91 De Zayas, A., A orillas, p. 394 y 396.

92 Se dio un caso de cinismo político por parte del ministro de Asuntos Exteriores ruso, el príncipe Alexei Lobanov-Rostovski, quien se pronunció al respecto en los siguientes términos: "A Rusia no le conviene crear en Asia una nueva Bulgaria». Esto certificaba una de las apreciaciones de De Zayas acerca de la cuestión armenia: éstos, a diferencia de los griegos, no contaban con el apoyo de ninguna de las potencias occidentales, con la excepción del ex-primer ministro británico William E. Gladstone, quien había abandonado el cargo en 1894 [De Zayas, A., A orillas, p. 54]. La postura de este político británico se explica por la postura anti-rusa mantenida durante toda su carrera parlamentaria. Sobre cómo vivió e interpretó el diplomático español los hechos que tuvieron lugar entre 1895-1896 y los inmediatamente anteriores, véase: De Zayas, A., A orillas, pp. 348-353.

93 Este acontecimiento tuvo cierto eco en la prensa española, como lo demuestra 
Jorge I como un hecho providencial, ante la pasividad de la flota internacional, fondeada en la bahía de la Suda, en el E. de Creta. Este golpe de mano convirtió, por orden de Abdülhamid II, la isla en un protectorado internacional, por el cual la Sublime Puerta conservaba su autoridad y Vassos se erigía en administrador de la población cristiana, bajo la atenta mirada de los británicos ${ }^{94}$.

Critica a todas las potencias implicadas, más preocupadas por los equilibrios de sus intereses en la región del Mediterráneo oriental que por el bienestar de los cristianos. Cita, entre otros muchos ejemplos, las relaciones económicas y militares entre la Alemania del kaiser Guillermo II y el Imperio otomano como uno de los motivos por los cuales no se intervino antes y con mayor contundencia ${ }^{95}$. Pero esto no salva al gobierno de Atenas y su ejército de las duras críticas por su inoperancia e ineptitud palmarias, causadas por su arrogancia desmedida ${ }^{96}$.

El «orientalismo greco-bizantino» que se ha ido desgranando a través de las páginas escritas por Antonio de Zayas Beaumont, parten de una mirada que no busca comprender el objeto de su semblanza, sino ofrecer una descripción descarnada, sin ningún atisbo de fascinación. Este aspecto es el que lo diferencia del «orientalismo clásico». No lo mueve una atracción morbosa, más bien al contrario: lo que subyace es una atracción por lo grotesco que puede resultar una civilización como la griega medieval y su correlato moderno y contemporáneo, vistos como una degeneración. Una reliquia del pasado que no ha sabido adaptarse al progreso de la civilización contemporánea. Que se han quedado al margen como las piezas de los museos. Restos arqueológicos que constituyen lo que para muchos era «el complicado problema de Oriente» ${ }^{97}$. Su imagen nace del regeneracionismo característico del fin de siglo hispano, pero lastrado por una fuerte impronta católica y conservadora.

la publicación de un artículo sobre la guerra greco-turca en la revista semanal Blanco y Negro, del 15 de mayo de 1897.

94 De Zayas, A., A orillas, pp. 386-387.

95 Véase: De Zayas, A., A orillas, p. 400; Clark, C., Sonámbulos, pp. 385-396.

96 De Zayas, A., A orillas, p. 405.

97 Estas son las palabras con las que A. de Zayas concluye su obra $A$ orillas del Bósforo. 
AA.VV. (1999), A History of the Hellenic Army (1821-1997), Atenas: Army History Directorate.

CLARK, C. (2014), Sonámbulos. Cómo Europa fue a la guerra en 1914, Barcelona: Galaxia Gutenberg.

CORREA RAMÓN, A. (2005), «Introducción» en De Zayas, A., Obra poética, edición de Amelina Correa Ramón, Sevilla: Fundación José Manuel Lara, pp. 11-99.

(2005), «La experiencia del Oriente Bizantino. Vida y literatura del poeta Antonio de Zayas de Beaumont», El viajero histórico 23, Granada: El Legado Andalusí.

DENY, J. (1986), «‘Abd al-Hamid II», Encyclopaedia of Islam (2nd edition), Leiden: E. J. Brill, vol. 1, pp. 63-65.

DE ZAYAS, A. (1902), Joyeles bizantinos, Madrid: Imprenta de A. Marzo. (1912), A orillas del Bósforo, Madrid: Imprenta de Juan Pueyo.

DIEHL, CH. (1948), Figures bizantines, 2 vols. París: Armand Colins (10 edición). FERNÁNDEZ UBIÑA, J. (1997), «Conflicto arriano y compromiso político en el episcopado latino del Bajo Imperio» en Moschos Morfakidis - Minerva Alganza Roldán (eds.), La religión en el mundo griego. De la Antigüedad a la Grecia Moderna, Granada: Athos-Pérgamos, pp. 221-248.

GARCÍA SANJUÁN, A. (2012), «Al-Andalus en la historiografía del nacionalismo españolista (siglos XIX-XXI). Entre la Reconquista y la España musulmana», en Diego Melo Carrasco - Francisco Vidal Castro (eds.), A 1300 años de la conquista de al-Andalus (711-2011). Historia, cultura y legado del Islam en la Península Ibérica, Coquimbo-Chile: Altazor, pp. 65-104.

HERRIN, J. (2002), Mujeres en la púrpura. Irene, Eufrosine y Teodora. Soberanas del medievo bizantino, Madrid: Taurus.

INALCIK, H (1995), «Rûmeli», Encyclopedia of Islam (2nd edition), Leiden: E. J. Brill, vol. 8, pp. 607-611.

KREISER, K. (1995), «Rûmeli Hissârî», Encyclopedia of Islam (2nd edition), Leiden: E. J. Brill, vol. 8, pp. 611-612.

LOUNGHIS, T. C. (2010), Byzantium in the Eastern Mediterranean: Safeguarding East Roman Identity (407-1204), Nicosia: Cyprus Research Centre.

MEYER, J. (2006), La gran controversia. Las Iglesias católica y ortodoxa de los origenes a nuestros días, Barcelona: Tusquets.

NEBOT NEBOT, J. V. (2013-2014), Antonio de Zayas. Poética y poesías parnasianas (1892-1902), tesis doctoral presentada en la Universitat Jaume I de Castellón.

PETERS, F. E. (2007), Los hijos de Abraham. Judaismo, Cristianismo, Islam, Barcelona: Laertes.

PRIMO CANO, C. (2010), «Calas en torno a la visión orientalista de Antonio de Zayas», Dicenda. Cuadernos de Filología Hispánica 28, pp. 153-184.

RUNCIMAN, S. (1956), Historia de las Cruzadas, 3 vols., Madrid: Revista de Occidente, vol. 1: La Primera Cruzada y la fundación del Reino de Jerusalén. 
TREADGOLD, W. (1995) Byzantium and its Army (284-1081), Stanford: Stanford University Press.

URSINUS, M. O. H., (1993), «Millet», Encyclopaedia of Islam (2nd edition), LeidenNueva York: E. J. Brill, vol. 7, pp. 61-64.

VALERA, J. (2007), Correspondencia, edición de Leonardo Romero Tobar (dir.), $\mathrm{M}^{\mathrm{a}}$ Ángeles Ezma Gil y Enrique Serrano Asenjo, 8 vols., Madrid: Castalia, vol. 6, Años 1895-1899.

VEIGA, F. (2006), El turco. Diez siglos a las puertas de Europa, Barcelona: Debate. 